\title{
The Transient Reappearance of Morphologically Normal M. Leprae in Patients Under Treatment
}

\author{
S. G. BROWNE, O.B.E., M.D., F.R.c.P., F.R.C.S., D.T.M. \\ Director, Leprosy Study Centre, London
}

The current interest in drug-resistance in leprosy consequent on the use of the elegant methods of demonstrating such resistance by the mouse foot-pad inoculation technique (Shepard, 1960; Rees, 1964), suggests that the time may be ripe for critical and experimental reassessment, as opportunity offers, of clinically-based claims or suspicions that resistance had developed to one or other of the drugs used in the treatment of leprosy. Many workers who follow the changes in morphology of $M$. leprae as seen in skin-smear preparations taken regularly by standard techniques, are impressed by the reappearance from time to time of 'solid rods' in patients with multibacillary leprosy treated with any of the drugs that have been in widespread use: dapsone (Cochrane, 1951; Wheate, 1960; British Med. J., 1960), thiacetazone (Davey, 1960; Le Khac Quyen et al., 1960), thiambutosine (Davey, 1960), diamino-diphenyl sulphoxide (Browne and Davey, 1961), Vadrine (Jopling and Ridley, 1951, 1958; Allen, 1961), ditophal (Davey, 1959; Davies and Driver, 1960), B 663 (Geigy) (Browne and Hogerzeil, 1962).

In some instances, but not necessarily, this reappearance of solid rods has coincided with the onset of an episode of acute exacerbation (Schujman, 1960). Some patients have shown this phenomenon after months or years of clinical and bacteriological quiescence, while in others the morphologically normal bacilli have reappeared in tissues that have never been entirely free from acid-fast bacilli, intact or abnormal. Some observers have demonstrated that clinical and bacteriological relapses are controllable by the same drug as was previously effective (Garrett, 1956, a and b), whereas others have used another drug on the assumption that the morphologically normal bacilli that had suddenly appeared were resistant to the first. With the object of postponing indefinitely or preventing completely the emergence of drugresistant strains of $M$. leprae, some workers have, advised the giving of more than one anti-leprosy drug (Dharmendra and Chatterjee, 1956; Floch 1966). Davey (1960) referred to an apparent decline in therapeutic activity during the second or third year of the exhibition of a drug, while other workers have emphasized the distinction to be drawn between the bactericidal or bacteriostatic action of a drug that resulted in a fall to zero of the Morphological Index, and the failure of the same drug to facilitate removal of effete mycobacteria from the tissues (Browne, 1967).

On the analogy of the drug treatment of other diseases, as Spencer Reed (1960) and others have pointed out, it would be most unlikely if resistance to drugs did not develop in leprosy. Until now, apart from the inconclusive method of continuing treatment with the suspected drug and observing no degenerative changes in $M$. leprae as seen in slit-smear preparations or histological sections, no scientifically convincing procedure has been available for demonstrating mycobacterial resistance to drugs used in leprosy. It is possible that instances of the transient reappearance of morphologically normal bacilli have been assumed to be examples of drug resistance.

REAPPEARANCE OF MORPHOLOGICALLY NORMAL FORMS OF $M$. leprae DETERMINATION

It is only when skin smears are regularly and

Reappearance of Normal Leprosy Bacilli 83 
skilfully examined at frequent intervals that the transient reappearance of morphologically normal forms is noted. At the Uzuakoli (Eastern Nigeria) Leprosy Research Unit, it was the practice to take smears from 6 skin and 2 nasal mucosal sites every month from patients with multi-bacillary leprosy (lepromatous, or highly positive borderline) participating in drug trials.

\section{CRITERIA}

Owing to the somewhat fortuitous nature of the smearing technique, it is possible that the point of the scalpel would from time to time take dermal material from atypical areas, and thus sometimes reveal residual nests of normal bacilli in tissue otherwise free from bacilli. However, when routine smears are taken from the same sites by a standard technique, and examined blind by the same skilled technician, normal bacilli are generally found to disappear from all the sites within a few months of each other (Browne, 1959, 1966). When normal forms continue to be absent from all the sites in 3 successful monthly smears, it is unlikely that small pockets of normal bacilli are being missed at these sites.

The criteria adopted in this study were these: complete absence for at least 5 months of solid rods in all the monthly smears from the 8 sites regularly smeared (i.e., the active edge of skin lesions (2), the anterior aspect of the thigh, the posterior aspect of the arm; both ear-lobes; both sides of the nasal septum) followed by the appearance of at least 5\% (an arbitrary figure) of solid rods in at least 3 successive monthly smears at one or more of the sites.

\section{FREQUENCY}

During a 4 year period, 78 patients out of a total under treatment of 500 with multibacillary leprosy, conformed to the above criteria. The population was 'selected' in the sense that all had been admitted as in-patients to the Uzuakoli Leprosy Research Unit. The frequency among the out-patients attending the district leprosy clinics is unknown.

\section{BACTERIOLOGICAL STATE OF THE PATIENTS}

There was no difference between the patients in whom solid rods made their reappearance and other patients, as far as the initial heights of the Bacterial and the Morphological Indexes were concerned, nor was there any difference between these groups in the rates of fall of the 2 Indexes.

DURATION OF TREATMENT BEFORE REAPPEARANCE OF SOLID RODS

Over $70 \%$ of the patients had had between 10 and 18 months' treatment before solid rods reappeared (average $12 \frac{1}{2}$ months), and no solid rods had been seen in the smears for at least 5 months.

In a small proportion of patients (about 10\%) solid rods appeared during the second 6 months of treatment; for the most part, these patients had had leprosy for a relatively short time. Special care was taken-because of the rapid disappearance of solid rods in patients with borderline leprosy - to ensure that all patients in this group were indeed suffering from lepromatous leprosy. In the remaining patients, the reappearance of normal forms was delayed for longer than 18 months, sometimes for much longer.

THE DURATION OF SOLID RODS IN THE MONTHLY SMEARS

After their reappearance, solid rods persisted in the monthly smears for an average of from 4 to 5 months, with the great bulk of the patients having solid rods in 3 successive monthly smears.

In half the patients, 2 groups of sites were affected, most of ten the skin and the ear-lobes; in a quarter, one site only was affected, and where this was the case, the nasal mucosa was by far the most frequent site to be solely affected; in the remaining quarter of the patients, sites in skin and ear-lobes and the nasal mucosa were affected. In some patients, on some occasions, most of the sites would show a few normal bacilli, the numbers varying from site to site; in other patients, many bacilli would be found at one site and none at all elsewhere.

\section{Leprosy Review}


PERCENTAGE OF SOLID RODS

In most patients, the average percentage of solid rods actually present in the smears varied from 5 (the minimum accepted as a basis in this investigation) to 20 . In some patients, $100 \%$ of a small number of bacilli (for instance, in material from the septal mucosa) might be morphologically normal, and these would disappear like those at other sites within 4 or 5 months on the average.

PERSISTENCE OF BACILLI

No conclusions can be drawn from this series as to the sites (skin, ear-lobes or nasal mucosa) where normal bacilli are most likely to persist.

ACCOMPANYing CONCENTRATion of $M$. leprae

There was no increase in the Bacterial Index in the great majority of patients, accompanying the reappearance of morphologically normal bacilli. In other words, the addition of normal forms was not of such a degree that the numerical assessment of the Bacterial Index was increased.

\section{PREVIOUS TREATMENT}

Solid rods reappear in patients irrespective of the drug used and the dosage used. During the period of this investigation, the commonest drugs given were dapsone, thiambutosine and B 663 (Geigy).

\section{SUBSEQUENT TREATMENT}

In most cases, the same drug was continued at the same dose, and the morphologically nor mal forms disappeared after the lapse of the period indicated above. In the case of ditophal, however, the reappearance of solid rods coincided with the patients' reduced enthusiasm for the evil-smelling compound, and dapsone was substituted for ditophal.

\section{DRUG RESISTANCE}

During the period under review, dapsone resistant bacilli were thought to have appeared in one patient. He had been re-admitted because of relapse following irregular and intermittent treatment. While taking dapsone under supervision, the lesions actually became worse and the proportion of normal bacilli in the monthly smears showed a steady increase. Since facilities for inoculation of material from this patient into mouse foot-pads were not then available, scientific proof of resistance is lacking. $\mathrm{He}$ improved on B 663 (Geigy), the solid rods disappearing from all sites smeared within a few months.

\section{DISCUSSION}

The patients in this group do not include those whose routine smears for many months showed numerous solid rods which eventually disappeared while the same treatment was continued. This slow bacteriologisal response may or may not be accompanied by a slow clinical response, and is to be distinguished from a relapse which is controllable by the same treatment as was previously effective.

The findings here reported cannot be explained by chance, by poor technique or a change of technicians. It seems that there may be from time to time a relatively sudden burst of activity of $M$. leprae that results in the appearance of solid rods at a rate faster than can be acted upon by the available drug. These bacilli are not resistant to the drug used, but an erroneous impression of resistance may be deduced if recourse is had at once to another anti-leprosy drug.

The reason for the sudden burgeoning of morphologically normal bacilli is not immediately apparent. At one stage, it was thought that climatic factors played a part, since most cases arose in the second quarter of the year when temperature and relative humidity were highest, but this explanation lacked conviction.

The observation that solid rods reappeared at several of the sites and thereafter disappearedall within a period averaging a little over 4 months-might indicate that some extraneous factor was operative. No obvious factor or single explanation suggests itself. It is possible that the dietary intake or the absorption of paraamino-benzoic acid may vory from season to season, necessitating different amounts of circulating or available dapsone.

Reappearance of Normal Leprosy Bacilli 
The microscopical situations where the normal bacilli have been lurking, unaffected by presumably inhibitory concentrations of drug in the tissues, are not disclosed on histological examination, except insofar as normal bacilli are frequently to be seen between the nerve fibres in the dermis, in the small dermal muscles, and in the endothelial cells of the small interrete blood plexuses. It may be that it is from these situations that normal bacilli suddenlyand in response to some unknown factor-begin to multiply more rapidly in a patient under therapy. As the bacilli become exposed to inhibitory concentrations of the drug employed, their sensitivity to the drug becomes apparent once again, and their subsequent history differs in no essential respect from that of bacilli that have already lived and died in situ. Rees (1963) has observed a similar chain of events in the case of $M$. leprae which may 'suddenly decide to multiply'.

\section{SUMMARY}

Morphologically normal $M$. leprae may reappear transiently at any of the sites habitually examined by the slit-smear technique. The most common time for this to occur is during the second year of treatment. There are generally no antecedents, clinical or bacteriological, to indicate that solid rods will reappear. There are usually no accompanying signs of acute exacerbation, and the total bacillary load is not as a rule greatly increased. The bacilli are not resistant to the drug given, and will disappear within a few months as treatment is continued with the same drug. The reappearance is to be detected only by the regular and careful examination of skin smears

\section{REFERENCES}

ALlen, J. A. (1961). Lep. Rev., 32, 191. BRIT. MED. J. (1960). Editorial, 2, 655. BROWNe, s. G. (1959). Lep. Rev., 30, 174. BROWNe, s. G. (1966). Lep. Rev., 37, 23.

BRowne, s. G. (1967). Trans. R. Soc. Trop. Med. Hyg., In the Press.

BRowne, S. G. and DAvey, T. F. (1961). Lep. Rev., 32, 194.

Browne, s. G. and Hogerzeil, t. M. (1962). Lep. Rev., $33,185$.

COCHRANe, R. G. (1951). Lep. Rev., 22, 64.

DAVEY, T. F. (1959). Lep. Rev., 30, 71.

DAvey, T. F. (1960). Trans. R. Soc. Trop. Med. Hyg., $54,199$.

DAvies, G. E. and Driver, G. w. (1960). Lep. Rev., $31,53$.

DHARMENDRA and CHATTERJEE, K. R. (1956). Leprosy in India, 27, 3.

Floch, H. A. (1966). Bull. Soc. Path. Exot., 59, 188. garrett, A. (1956). Lep. Rev., 27, 58.

garrett, A. (1956). Lep. Rev., 27, 178.

JOPLING, w. and RIDLEY, D. s. (1958). Lep. Rev., 29, 143. JOPLING, w. and RIDLEY, D. s. (1961). Lep. Rev., 32, 188. LE KHAC QUYEN, BUU-HOI, N. P. and XUONG, N. D. (1960).

Bull. Acad. Nat. Méd., 144, 535-538.

REED, SPENCER (1960). Brit. Med. J., 2, 1672.

ReEs, R. J. W. (1963). The Prthogenesis of Leprosy.

Ciba Foundation Study Group No. 15. London.

J. \& A. Churchill Ltd.

REes, R. J. w. (1964). Brit. J. Exp. Path. 45, 207.

ShePard, C. C. (1960). Amer. J. Hyg., 71, 147.

sCHUJMAN, s. (1960). Leprología, 5, 32.

wheate, H. w. (1951). Lep. Rev., 22, 80. 